MINERALOGIA, 39, No. 1-2: 31-40 (2008)

DOI: $10.2478 / v 10002-008-0001-9$

www.Mineralogia.pl

MINERALOGICAL SOCIETY OF POLAND

Review paper

\title{
Synchrotron microanalytical methods in the study of trace and minor elements in apatite
}

\author{
John RAKOVAN ${ }^{1}$ *, Yun LUO ${ }^{1}$, Olaf BORKIEWICZ1 \\ ${ }^{1}$ Department of Geology, Miami University, Oxford, Ohio, USA 45056; e-mail: Rakovajf@muohio.edu \\ * Corresponding author
}

Received: August 09, 2007

Accepted: April 02, 2008

\begin{abstract}
Synchrotron X-ray facilities have the capability for numerous microanalytical methods with spatial resolutions in the micron to submicron range and sensitivities as low as ppm to ppb. These capabilities are the result of a high X-ray brilliance (many orders of magnitude greater than standard tube and rotating anode sources); a continuous, or white, spectrum through the hard X-ray region; high degrees of X-ray columniation and polarization; and new developments in X-ray focusing methods. The high photon flux and pulsed nature of the source also allow for rapid data collection and high temporal resolution in certain experiments. Of particular interest to geoscientists are X-ray fluorescence microprobes which allow for numerous analytical techniques including X-ray fluorescence (XRF) analysis of trace element concentrations and distributions; X-ray absorption spectroscopy (XAS) for chemical speciation, structural and oxidation state information; X-ray diffraction (XRD) for phase identification; and fluorescence microtomography (CMT) for mapping the internal structure of porous or composite materials as well as elemental distributions (Newville et al. 1999; Sutton et al. 2002; Sutton et al. 2004).

We have employed several synchrotron based microanalytical methods including XRF, microEXAFS (Extended X-ray Absorption Fine Structure), microXANES (X-ray Absorption Near Edge Structure) and CMT for the study of minor and trace elements in apatite (and other minerals). We have also been conducting time resolved X-ray diffraction to study nucleation of and phase transformations among precursor phases in the formation of apatite from solution at earth surface conditions. Summaries of these studies are given to exemplify the capabilities of synchrotron microanalytical techniques.
\end{abstract}

Key-words: synchrotron, microanalysis, XRF, EXAFS, XANES, apatite

\section{Introduction}

With the recognition of significant compositional, structural and isotopic heterogeneities in minerals, and for the study of increasingly smaller mineral grains, mineralogists and geo- 
scientists are turning more and more to microanalytical techniques. Synchrotron X-ray facilities have the capability for numerous microanalytical methods with spatial resolutions in the micron to submicron range and sensitivities as low as ppm to ppb. These capabilities are the result of a high X-ray brilliance (many orders of magnitude greater than standard tube and rotating anode sources); a continuous, or white, spectrum through the hard X-ray region; high degrees of X-ray columniation and polarization; and new developments in X-ray focusing methods. The high photon flux and pulsed nature of the source also allow for rapid data collection and high temporal resolution in certain experiments. Of particular interest to geoscientists are X-ray fluorescence microprobes which allow for numerous analytical techniques including X-ray fluorescence (XRF) analysis of trace element concentrations and distributions; X-ray absorption spectroscopy (XAS) for chemical speciation, structural and oxidation state information; X-ray diffraction (XRD) for phase identification; and fluorescence microtomography (CMT) for mapping the internal structure of porous or composite materials as well as elemental distributions (Newville et al. 1999; Sutton et al. 2002; Sutton et al. 2004). Sample preparation can be minimal and analyses are routinely done in air and water. Of the numerous focusing techniques available for X-rays the use of Kirkpatrick-Baez (KB) micro-focusing mirrors has distinct advantages for use in microprobe beamlines including achromaticity (all energies are focused to the same spot), orders of magnitude increases in flux density, and long working distances (Eng et al. 1998).

We have employed several synchrotron based microanalytical methods including X-ray fluorescence microanalysis, microEXAFS (Extended X-ray Absorption Fine Structure), microXANES (X-ray Absorption Near Edge Structure) and microtomography for the study of minor and trace elements in apatite (and other minerals). We have also been conducting time resolved $\mathrm{X}$-ray diffraction to study nucleation of and phase transformations among precursor phases in the formation of apatite from solution at earth surface conditions. These studies have been conducted primarily at the dedicated microprobe facilities at the X26A and X27A beamlines of the National Synchrotron Light Source (NSLS), Brookhaven National Laboratory, Upton, New York, USA and Sector 13 of the Advanced Photon Source (APS), Argonne National Laboratory, Argonne, Illinois, USA. These facilities have operating ranges from 4-30 and 4-50 KeV respectively, with energy discrimination from the white beam of approximately $1 \mathrm{eV}$. All three of these facilities utilize Kirkpatrick-Baez (KB) mirrors for focusing the X-ray beam to roughly $5 \mu \mathrm{m}$ and $1 \mu \mathrm{m}$, respectively. The minimum detection limits are approximately $0.01 \mathrm{mg} \cdot \mathrm{kg}^{-1}$ $(10 \mathrm{ppb})$ in $30 \mathrm{pg}$ samples and $1 \mathrm{ppm}$ for microXRF at sector 13 of the APS and X26 at the NSLS respectively. For microXANES, a concentration of $\sim 10 \mathrm{mg} \cdot \mathrm{kg}^{-1}$ and $100-1000 \mathrm{mg} \cdot \mathrm{kg}^{-1}$ for microEXAFS at the APS and $100 \mathrm{mg} \cdot \mathrm{kg}^{-1}$ and $0.1-1 \mathrm{wt} \%$ for X26A are required (Sutton et al. 2002; Sutton et al. 2004). Below is a sampling of studies from our group that exemplify some of the capabilities of mineral microanalysis at synchrotron facilities. Numerous types of detectors are used for X-ray fluorescence. With trace and minor constituents multi-element, solid state, energy-dispersive detectors ( $\mathrm{Ge}$ or $\mathrm{Li}$ drifted $\mathrm{Si}$ ) are most commonly used. Because of the desire to analyze REE in natural mineral samples, much of our work has employed wavelength dispersive (WDS) detectors. This, however, is not routine and incorporation of WDS detection as standard equipment at synchrotron microprobe facilities will greatly benefit geochemists who commonly are concerned with the study of REE in minerals and rocks. 


\section{Applications of Microanalytical Techniques}

\subsection{MicroXRF mapping}

Trace element distributions in crystals can give us information about changes in the environment during crystal growth, internal morphology and the morphologic history of a crystal, growth mechanisms, growth rate anisotropies and structural differences between different regions of a crystal surface. We have used spatially resolved (1-10 $\mu \mathrm{m}$ beam size) XRF line and area scans to map out the concentration variability (zoning) of trace elements in apatite and fluorite surfaces and crystal sections (e.g. Figs. 1 and 2). Results show crystal face specific incorporation leading to sectoral zoning, and more fundamentally, step specific incorporation leading to intrasectoral zoning and sectoral zoning (Rakovan and Reeder 1994, 1996; Reeder and Rakovan 1999; Bosze and Rakovan 2002; Rakovan 2002).

The partitioning behavior of REE between apatite subsectors associated with symmetrically nonequivalent growth steps was found to be correlated with the size of the REE ion relative to $\mathrm{Ca}^{2+}$, for which it substitutes in the structure. All of the trace elements observed in the apatites studied exhibit sectoral and intrasectoral zoning, except for Eu in the samples from Llallagua, Bolivia. It was speculated that this anomalous behavior is the result of roughly equivalent proportions of $\mathrm{Eu}^{2+}$ and $\mathrm{Eu}^{3+}$ in the crystals, assuming that the distribution coefficients between subsectors for $\mathrm{Eu}^{2+}$ and $\mathrm{Eu}^{3+}$ are approximately the inverse of one another.

\subsection{MicroXANES mapping}

To test the hypothesis that the anomalous intracrystalline partitioning of Eu was due to equal and opposite zoning trends of $\mathrm{Eu}^{2+}$ and $\mathrm{Eu}^{3+}$, Eu microXANES line scans were conducted over symmetrically nonequivalent vicinal faces of growth hillocks on the (100) surface (e.g. Fig. 3) (Rakovan et al. 2001). A total of 10 points were collected within each of the subsectors under the two vicinal faces, for a total of 20 points per line scan. X-ray absorption measurements were made at station 13ID of the APS.

The XANES data in Figure 3 show that the total concentration of Eu is larger in the [011] subsector relative to the [001] subsector, however, this difference is smaller than the variation found within a single subsector, thus is not indicative of intrasectoral zoning. The $\mathrm{Eu}^{2+} / \mathrm{Eu}^{3+}$ ratios are very similar in the two sectors, which would not be expected if differential incorporation, with opposite partitioning trends, occurred for the two states during crystal growth. The anomalous lack of intrasectoral zoning of $\mathrm{Eu}^{2+}$ and $\mathrm{Eu}^{3+}$ is difficult to explain given that the Llallagua apatites exhibit intrasectoral zoning of all of the other REE. One possibility that is being investigated is that $\mathrm{Eu}^{2+}$ and $\mathrm{Eu}^{3+}$ were differentially incorporated during growth, but post growth processes changed the oxidation state of Eu throughout the crystal to an equilibrium ratio measured in the micoXANES experiments.

\subsection{Fluorescence microtomography}

Trace element distributions can also be determined in three dimensions using fluorescence microtomography. This was done in a related study of $\mathrm{Ni}$ and $\mathrm{Fe}$ distributions in synthetic 


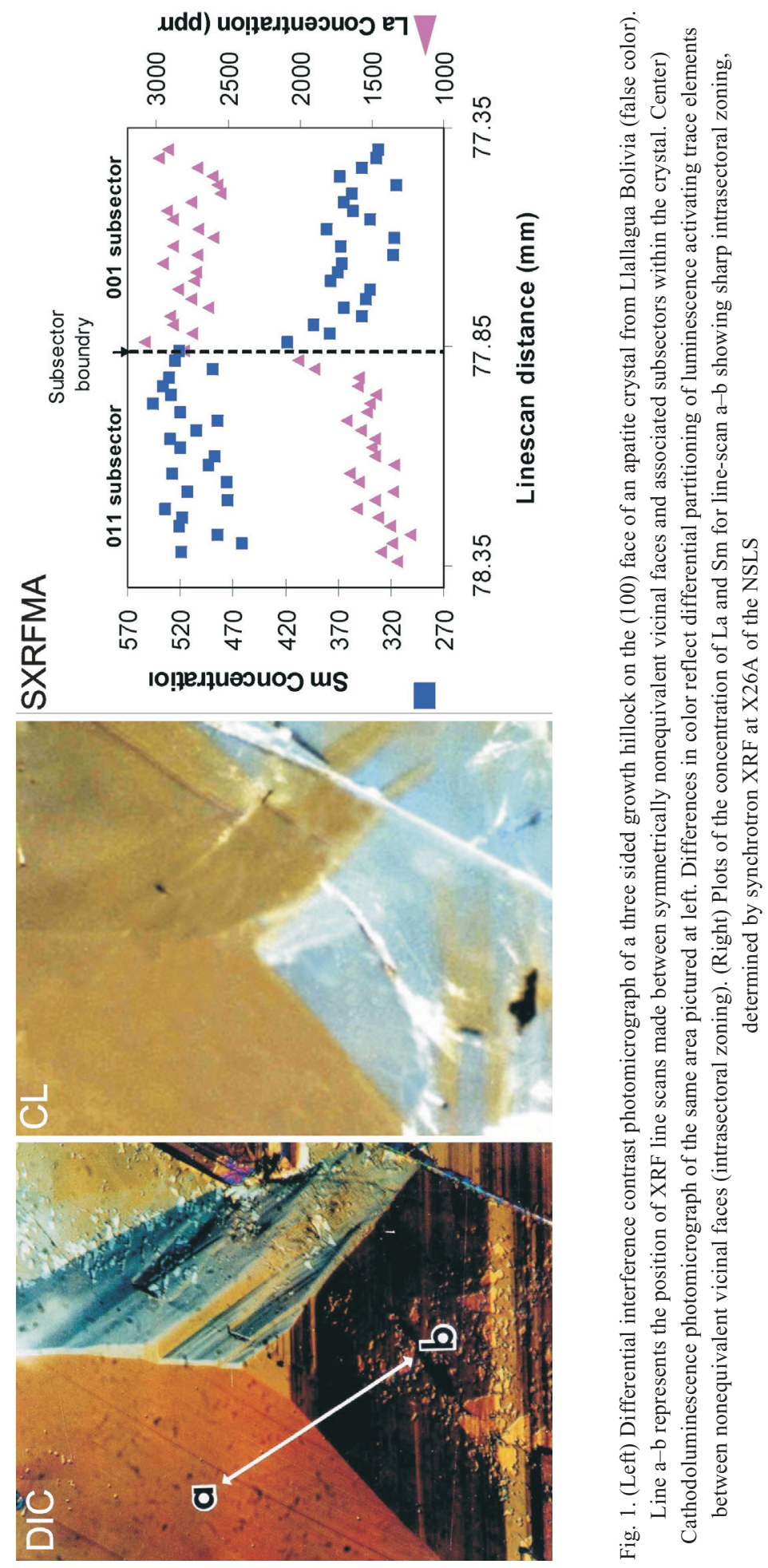


diamonds (Meng et al. 2003). XRF tomographic slices were generated by rotating the diamond crystal around the [1 $1 \overline{1} 0]$ axis at angles between 0 and $180^{\circ}$ in $3^{\circ}$ increments. At each angular increment XRF area scans (with $4 \mu \mathrm{m}$ step sizes) were collected; the transmission intensity through the diamond was recorded as well as the integrated $\mathrm{FeK} \alpha$. and $\mathrm{NiK} \alpha$. fluorescence
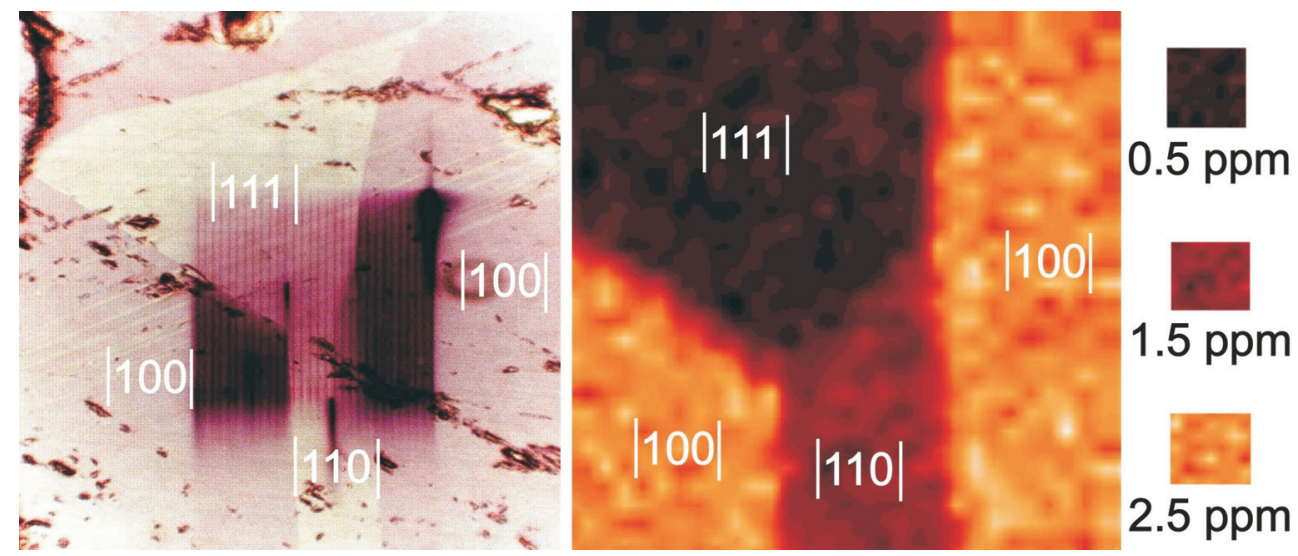

Fig. 2. (Left) Optical photomicrograph of thin section through a single fluorite crystal from the Hansonburg Mining District, Bingham, New Mexico, USA. Dark lines are the result of color center formation by the scanned synchrotron X-ray beam. (Right) Plot of the concentration of Er for the scanned area on the right, determined by synchrotron XRF at X26A of the NSLS. Concentration differences correlate with the (111), (100) and (110) sectors (i.e. sectoral zoning)
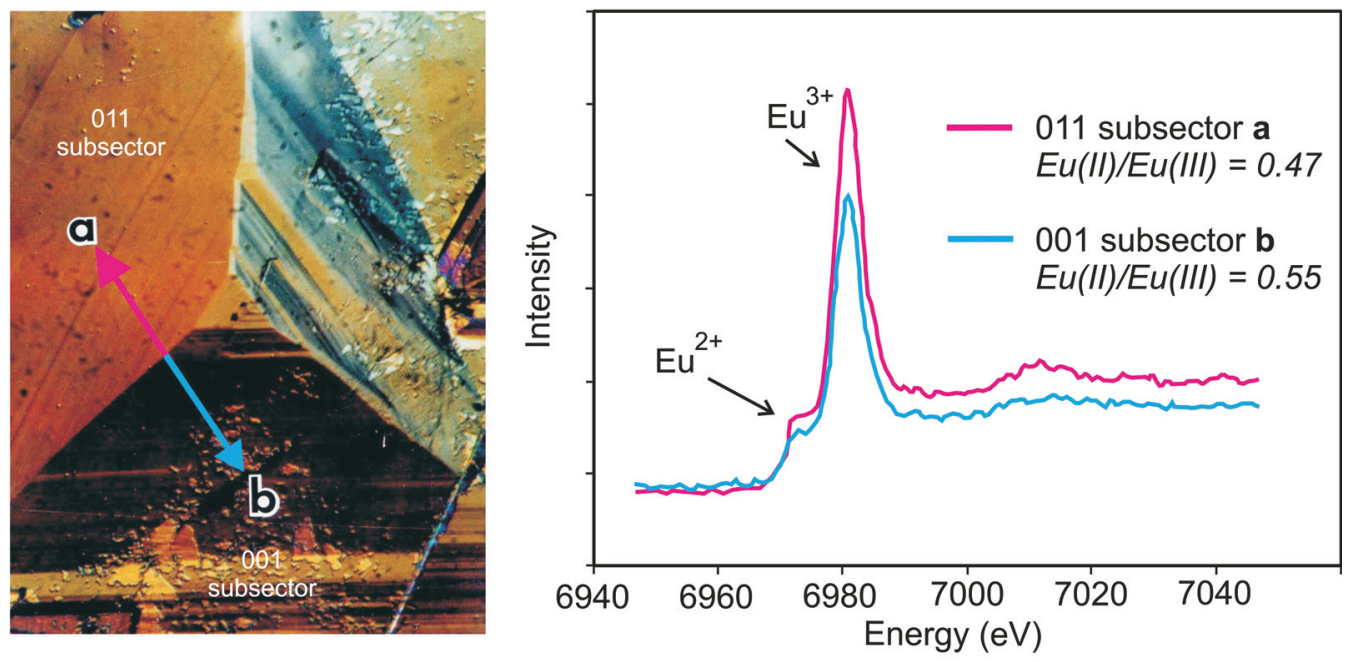

Fig. 3. (Left) Differential interference contrast photomicrograph of a three sided growth hillock on the (100) face of an apatite crystal from Llallagua Bolivia. Line $a-b$ represents the position of XRF line scans made between symmetrically nonequivalent vicinal faces and associated subsectors within the crystal.

(Right) The average Eu L3-edge microXANES spectra of 10 points along the pink segment of the line scan, 011 subsector, and 10 points along the blue segment of the line scan, 001 subsector. Both subsectors show heterovalent Eu concentrations with roughly the same $2+: 3+$ ratio 

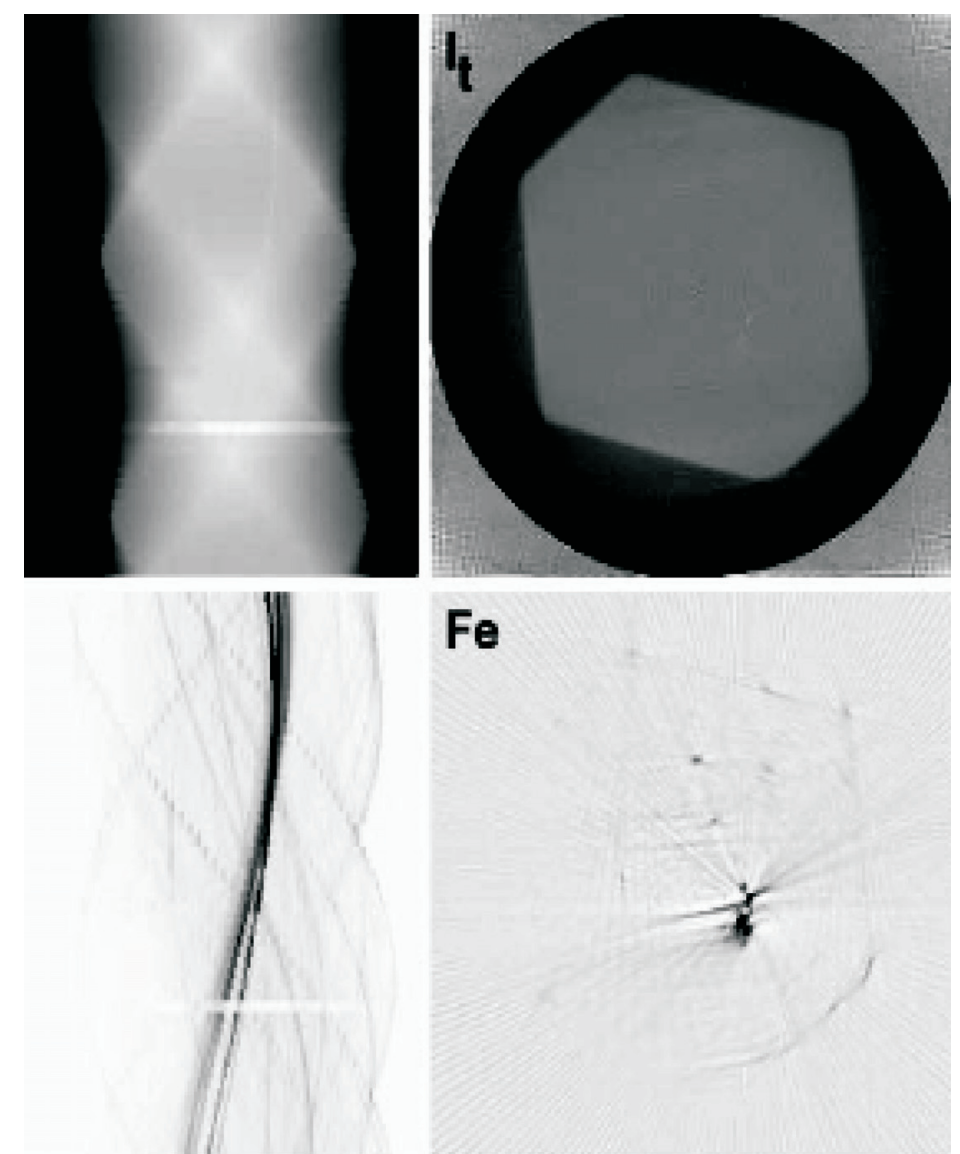

Fe
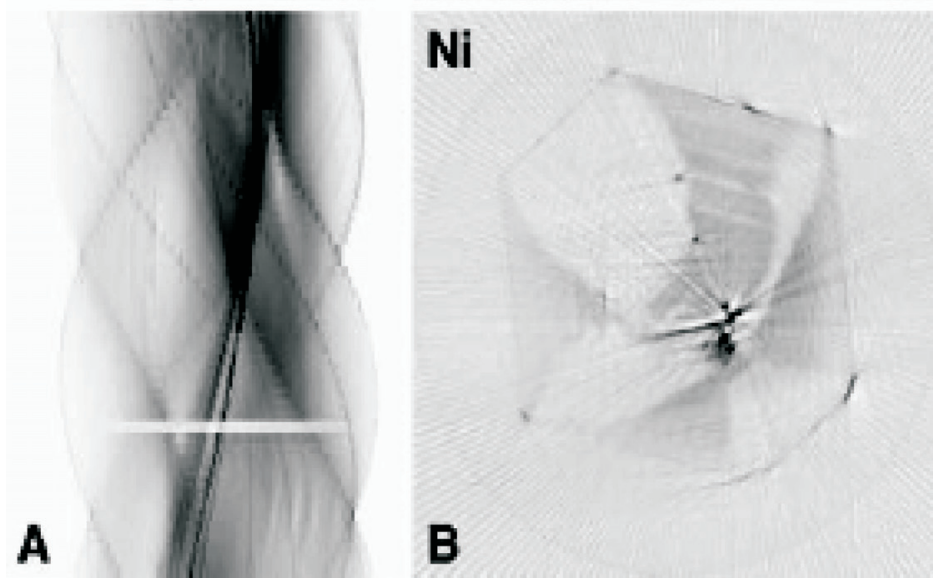

Fig. 4. Transmission and Fluorescence Tomograms

(A) Sinograms: maps of intensity as a function of position X (ordinate) and angle $\theta$. (abscissa) - for transmitted intensity (top), FeK $\alpha$ fluorescence (middle), and NiK $\alpha$ fluorescence (bottom).

(B) Reconstructed slices through the diamond, showing intensities as a function of position (X, Y). From Meng et al. (2003) 
intensity. These data were used to create "sinograms" (maps of intensity as a function of angle, $\theta$, and lateral position, $x$ ) of transmission, and Fe and Ni fluorescence intensity (Fig. 4A). Sinograms were transformed to virtual slices of total density as well as partial densities for $\mathrm{Fe}$ and $\mathrm{Ni}$ in the plane of the X-ray beam (Fig. 4B). The resulting data show drastically different behavior for Fe and Ni. Nickel was found to be sector-zoned, with concentrations in $\{111\}$ growth sectors at least 3 times those in $\{100\}$ sectors. Iron, however, exists in the form of microaggregates with an essentially homogenous distribution within the crystal.

\subsection{MicroEXAFS}

Thorium and uranium in apatite have been used extensively in geochronologic and petrogenetic studies for decades. Because of its high affinity for these and other radionuclides, its relatively low solubility in aqueous solutions, its thermal stability, and its thermal annealing behavior, there is also great interest in apatite as a solid nuclear-waste form and a metal sequestration agent. Fundamental to our understanding of actinide retention and release by apatite are crystal chemical parameters such as site occupancy and structural distortions created by these substituents. Despite the interest in Th and U in apatite, the basic crystal chemistry of these substituents in the structure was previously unknown. A combination of single crystal XRD and EXAFS spectroscopy is being used to probe the crystal chemistry and local structure of these actinides in natural and synthetic apatites (Rakovan et al. 2002; Luo et al. in rev. and in prep.). Because of the small size $(20-100 \mu \mathrm{m})$ and small volume of our synthetic samples, microEXAFS is required, however, single crystal microEXAFS suffers from polarization effects (Fig. 5). In order to interpret the polarized microEXAFS data from our single crystals, it is necessary to know the crystallographic orientation of the sample with respect to the polarization direction of X-ray beam during data collection. To do this we have designed and built a portable goniometer that duplicates the geometry of our laboratory Bruker APEX diffractometer goniometer. Crystal orientation is determined by X-ray diffraction at our home institution. The portable goniometer is then setup on the experimental table at synchrotron facilities and the crystal can be set in any specific, known orientation (Fig. 6). EXAFS data have allowed us to
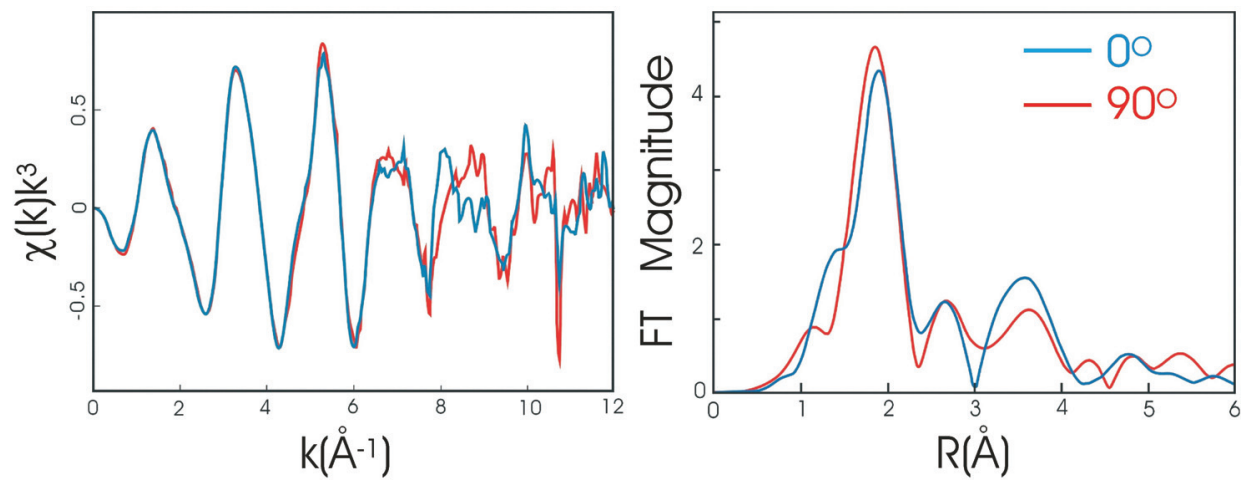

Fig. 5. (Left) Th $L 3$-edge microEXAFS from a $50 \mu \mathrm{m}$ single apatite crystal collected in two different orthogonal orientations (red and blue). (Right) Fourier transform magnitudes (not corrected for phase shifts) of EXAFS on left. Differences is peak heights and positions are the result of polarization effects in single crystal EXAFS 


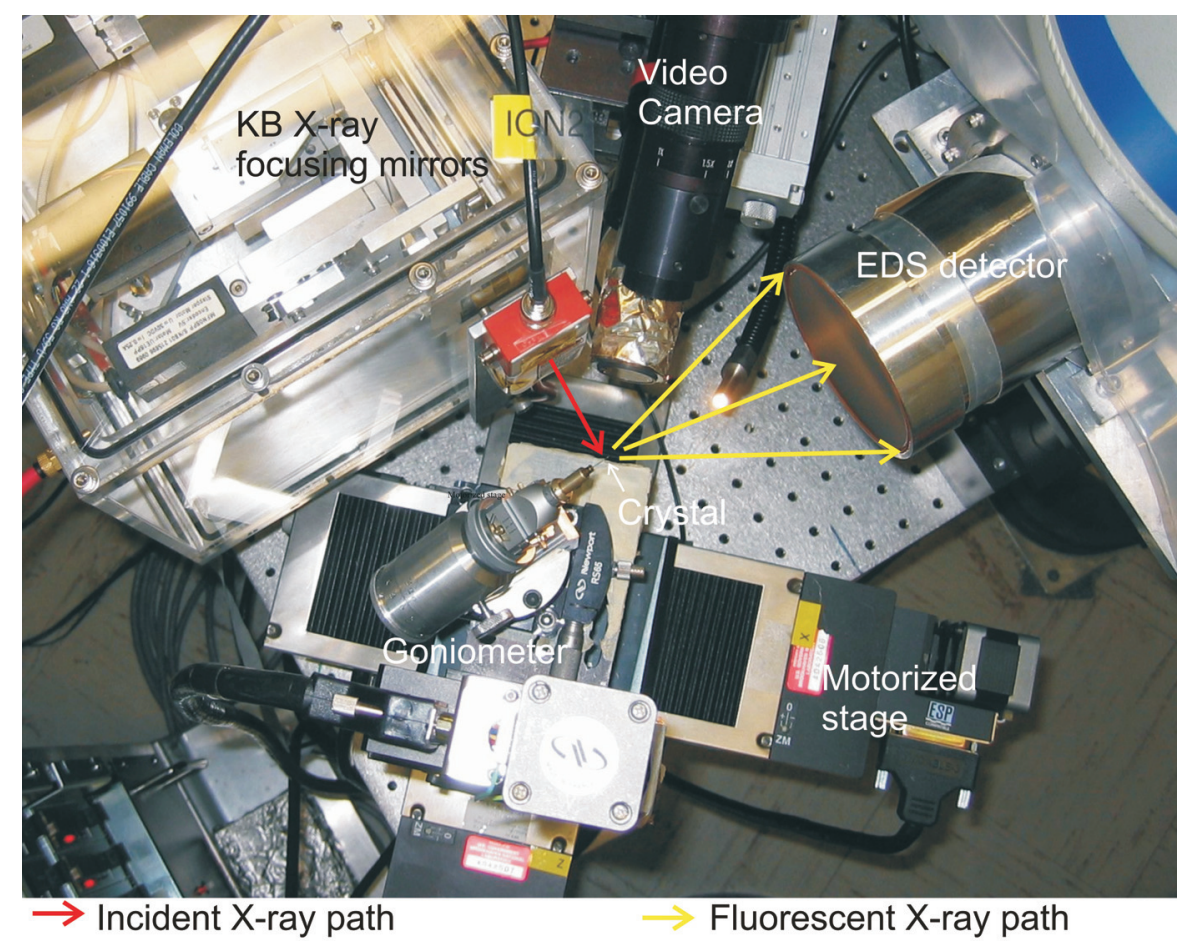

Fig. 6. Portable goniometer setup for crystal orientation during microEXAFS data collection, NSLS X27A experimental hutch

determine the site(s) of actinide occupation within the apatite structure, and the local distortion of the sites due to these substituents including changes in coordination and bond lengths.

\subsection{Time resolved diffraction}

Metal coprecipitation with apatite at low temperatures is being investigated as a potential sequestration and stabilization strategy for contaminated soils and ground waters. However, at conditions found in Earth surface environments apatite formation is preceded by crystallization of precursor Ca-phosphate phases. The effect of such precursors on metal sequestration and retention has previously never been evaluated. As part of our work on this problem we have been using in-situ time resolved X-ray diffraction studies of apatite formation pathways from aqueous solutions, performed at the X7B beamline of the NSLS (Fig. 7) (Borkiewicz et al. in prep.). A series of experiments with different $\mathrm{Ca} / \mathrm{P}$ and liquid/solid ratios in the starting material, different temperatures, and with different metals ( $\mathrm{U}, \mathrm{Zn}, \mathrm{Mn}, \mathrm{Sr}$ ) have been performed. The initial precipitate was identified as brushite $\left(\mathrm{CaHPO}_{4} \cdot 2 \mathrm{H}_{2} \mathrm{O}\right)$ in all experiments, independent of the initial $\mathrm{Ca} / \mathrm{P}$ ratio in solution. In the experiment conducted at ambient temperature brushite was the only phase present in the solution/slurry throughout the duration of the analysis ( $12 \mathrm{hrs})$. Under the conditions of elevated temperature $\left(90^{\circ} \mathrm{C}\right)$, however, a sequence of phase transitions, from brushite to apatite with intermediate monetite $\left(\mathrm{CaHPO}_{4}\right)$ was observed. The pathway of the transitions and the final product are independent of both the 


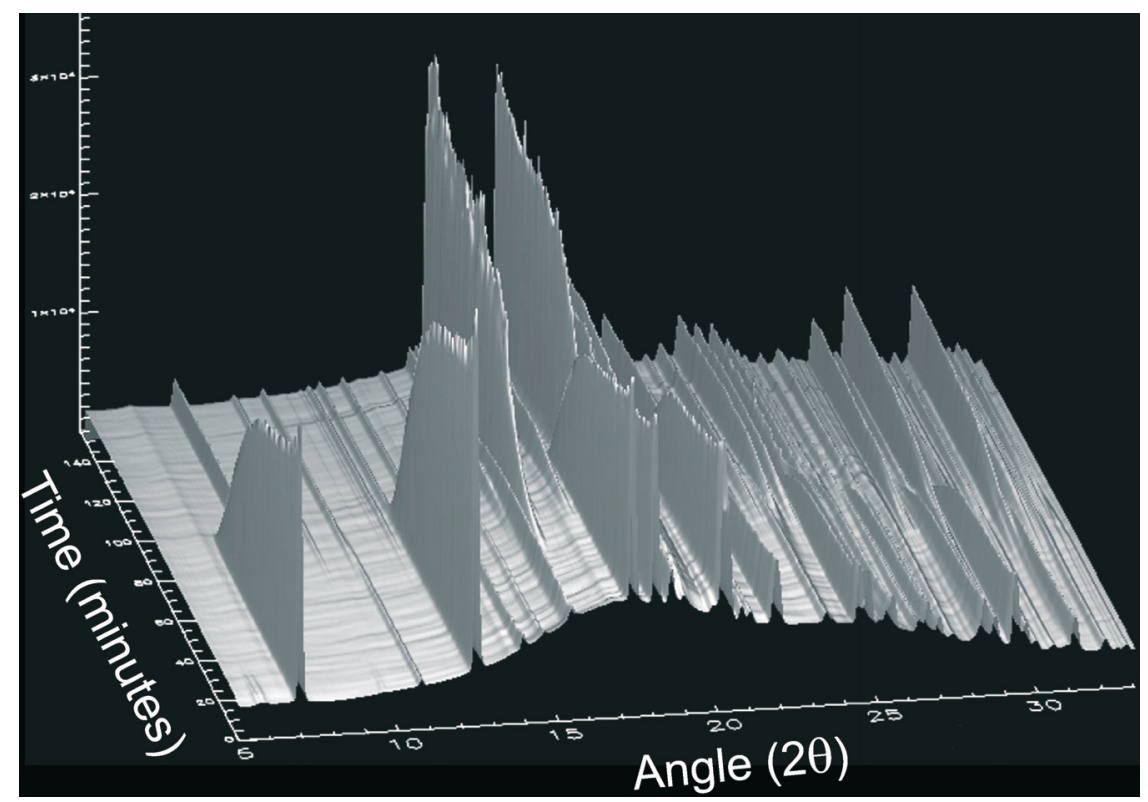

Fig. 7. Time resolved powder XRD of the precipitation of calcium phosphates from solution $\left(90^{\circ} \mathrm{C}, 9 \mathrm{hrs}\right.$ of data, patterns collected every 3 minutes). The initial precipitate is brushite and an amorphous calcium phosphate. These transform to monetite and then to hydroxylapatite over time

$\mathrm{Ca} / \mathrm{P}$ ratio and the temperature of the reaction. The rate of the transformation, however, increased with increasing temperature. The compatibility of the heavy metals with initially formed brushite and intermediate monetite may ultimately be of greater significance for the fate and transport of these toxic species in the environment than their compatibility with apatite.

These are just a few examples, from our research only, of the types of microanalytical studies possible at synchrotron sources, especially at dedicated microprobe facilities. A much more comprehensive review of synchrotron applications in Earth and environmental studies can be found in Fenter et al. (2002).

\section{References}

BORKIEWICZ O., CAHILL C., RAKOVAN J., In preparation: In situ, time-resolved synchrotron X-ray diffraction of calcium phosphates during nucleation and growth from aqueous solution.

BOSZE S., RAKOVAN J., 2002: Surface structure controlled sectoral zoning of the Rare Earth Elements in fluorite from Long Lake, N.Y. and Bingham, N.M. Geochimica et Cosmochimica Acta 66, 997-1009.

ENG P.J., NEWVILlE M., RIVERS M.L., SUTTON S.R., 1998: Dynamically figured Kirkpatrick Baez X-ray micro-focusing optics. In I. McNult, Ed., X-Ray Microfocusing: Applications and Technique, SPIE Proceeding $3449,145-156$.

FENTER P., RIVERS M., STURCHIO N., SUTTON S. (Eds.), 2002: Applications of Synchrotron Radiation in Low-Temperature Geochemistry and Environmental Science Reviews in Mineralogy and Geochemistry V. 49. Mineralogical Society of America. Washington, DC. 579p.

LUO Y., RAKOVAN J., HUGHES J., PAN Y., In review: A. Site preference of U and Th in Cl, F, Sr apatites. American Mineralogist. 
LUO Y., RAKOVAN J., ELZINGA E., PAN Y., LUPULESCU M.V., HUGHES J., In preparation: Crystal chemistry of Th in natural and synthetic fluorapatite. American Mineralogist.

MENG Y., NEWVILLE M., SUTTON S., RAKOVAN J, MAO H.K., 2003: Fe and Ni impurities in synthetic diamond. American Mineralogist 88, 1555-1559.

NEWVILLE M., SUTTON S.R., RIVERS M.L., ENG P.J.J., 1999: Micro-beam X-ray absorption and fluorescence spctroscopies at GSECARS: APS beamline 13ID. Journal of Synchrotron Radiation 6, 353-355.

RAKOVAN J., 2002: Growth and Surface Structure of Apatite. In: Phosphates: Geochemical, Geobiological and Materials Importance, Kohn, M., Rakovan, J., Hughes, J.M. (eds). Reviews in Mineralogy and Geochemistry V. 48. Mineralogical Society of America. Washington, DC. p. 51-86.

RAKOVAN J., REEDER R.J., 1994: Differential incorporation of trace elements and dissymmetrization in apatite: The role of surface structure during growth. American Mineralogist 79, 892-903.

RAKOVAN J., REEDER R.J., 1996: Intracrystalline Rare Earth Element distributions in apatite: Surface structural influences on zoning during Growth. Geochimica et Cosmochimica Acta 60, 4435-4445.

RAKOVAN J., NEWVILLE M., SUTTON S., 2001: Wavelength dispersive XANES of heterovalent Eu in Llallagua apatite. American Mineralogist 86, 697-700.

RAKOVAN J., REEDER R.J., ELZINGA E.J., CHERNIAK D., TAIT C.D., MORRIS D.E., 2002: Characterization of $\mathrm{U}(\mathrm{VI})$ in the apatite structure by X-ray absorption spectroscopy. Environmental Science and Technology 36, 3114-3117

REEDER R.J., RAKOVAN J., 1999: Surface structural controls on trace element incorporation during crystal growth In: Growth, Dissolution and Pattern-formation in Geosystems, B. Jamtveitand P. Meakin (eds.) p. 143-162. Kluwer Academic Publishers.

SUTTON P.R., BERTSCH P.M., NEWVILLE M., RIVERS M., LANZIROTTI A., ENG P., 2002: Microflourescience and microtomography analyses of heterogeneous earth and environmental materials. In: P.A. Fenter, M.L. Rivers, Sturchio, N.C., and Sutton, S.R. Eds., Applications of Synchrotron Radiation in Low-Temperature Geochemistry and Evironmental Sciences, 49, 429-483. Reviews in Mineralogy and Geochemistry, Washington, D.C.

SUTTON S.R., NEWVILLE M., ENG P., RIVERS M., LANZIROTTI A., 2004: Mirror-based X-ray fluorescence microprobes at the Advanced Photon Source and the National Synchrotron Light Source. Advances in X-ray Analysis 47, 76-83. 